\title{
CONSERVACIÓN Y APROVECHAMIENTO DE BEAUCARNEA RECURVATA, ESPECIE FORESTAL NO MADERABLE
}

\section{A. Contreras, M. L. Osorio, M. Equibua y G. Benitez}

Laboratorio de Ecología Aplicada, Instituto de Ecología A. C. Km. 2.5 Carretera Antigua a Coatepec 91070, Xalapa, Veracruz, MéXico

\section{INTRODUCCIÓN}

Beaucarnea recurvata Lemaire (1861) (monja o pata de elefante) de la familia Nolinaceae, es una especie de importancia ornamental, catalogada como amenazada y protegida por el Estado Mexicano (NOM-059SEMARNAT), debido a que las semillas, individuos juveniles y adultos, se comercializan ilegalmente. Habita en la selva baja caducifolia, considerada zona de refugio de biodiversidad, hábitat que presenta un acelerado cambio en el uso del suelo por la ampliación de la frontera agrícola, pecuaria y urbana.

Con base en estudios previos sobre la dinámica de la especie se ha diseñado una estrategia de su produc-
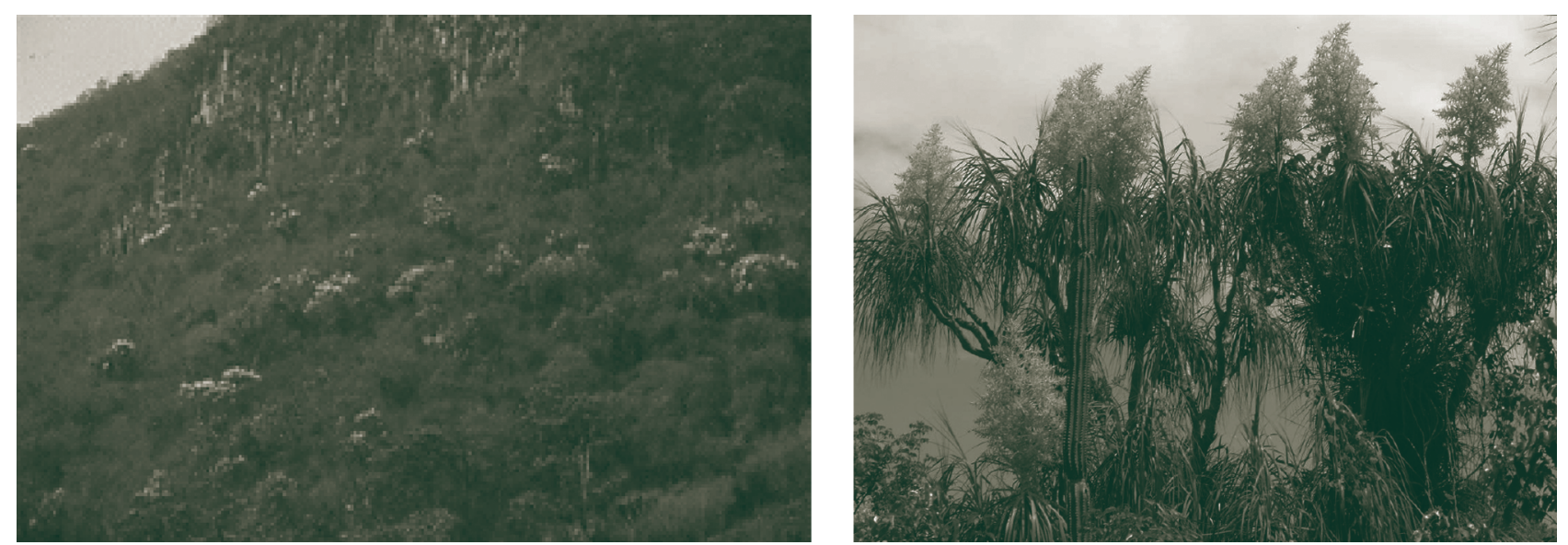

Figura 1. Floración masiva de la monja e individuo reproductivo. 
ción y conservación, a través del establecimiento en 2004 de una Unidad de Manejo y Aprovechamiento de Vida Silvestre, llamada "3 de Mayo" ubicada en la localidad de Loma de Rogel, Municipio de Emiliano Zapata (Veracruz, México).

La voluntad de reconvertir la producción convencional -agrícola o ganadera- centrada en el aprovechamiento de un producto en sistemas múltiples que integran la agricultura, la ganadería y el aprovechamiento forestal de diversas especies, permitirá la restauración y conservación del hábitat. La comercialización de la biodiversidad en viveros campesinos, contribuirá a la generación de empleo y de ingresos económicos adicionales a partir de manejo sustentable de sus recursos naturales.

La realización de un plan integral de manejo de los recursos naturales disponibles para una comunidad, supone el conocimiento de los aspectos espaciales y temporales de los recursos de interés, es decir, conocer su historia, la dinámica de su desarrollo, aprovechamiento y su arreglo o disposición en el espacio comunitario (BOCCO, 1998).

Los retos en el campo de la producción y la conservación de los recursos naturales, requieren de una profunda reflexión, investigación y recursos humanos altamente capacitados. Uno de los principales desafíos de las instituciones de enseñanza e investigación es generar ideas, sistemas, metodologías y capacidades que faciliten que las sociedades mejoren su nivel de vida y convivan en armonía con su ambiente (AGUIRRE, 1993).

La diversificación de la producción, entendida como el aprovechamiento de conjuntos amplios de especies en el espacio y el tiempo, es una alternativa de desarrollo para el rescate y habilitación de áreas que han sido alteradas por actividades humanas, entre ellas la agrícola y la pecuaria (CONTRERAS \& BARRERA, 2007). Las regiones tropicales del país, principalmente la región sureste, son áreas con un gran potencial para implementar actividades de diversificación de la producción, debido al uso de terrenos agropecuarios extensivos en áreas con pendientes pronunciadas (SEMARNAT, 2002a).

El objetivo del estudio es evaluar el estado de conservación y aprovechamiento de cinco poblaciones de Beaucarnea recurvata, sus requerimientos ecológicos y su importancia en la selva baja caducifolia.
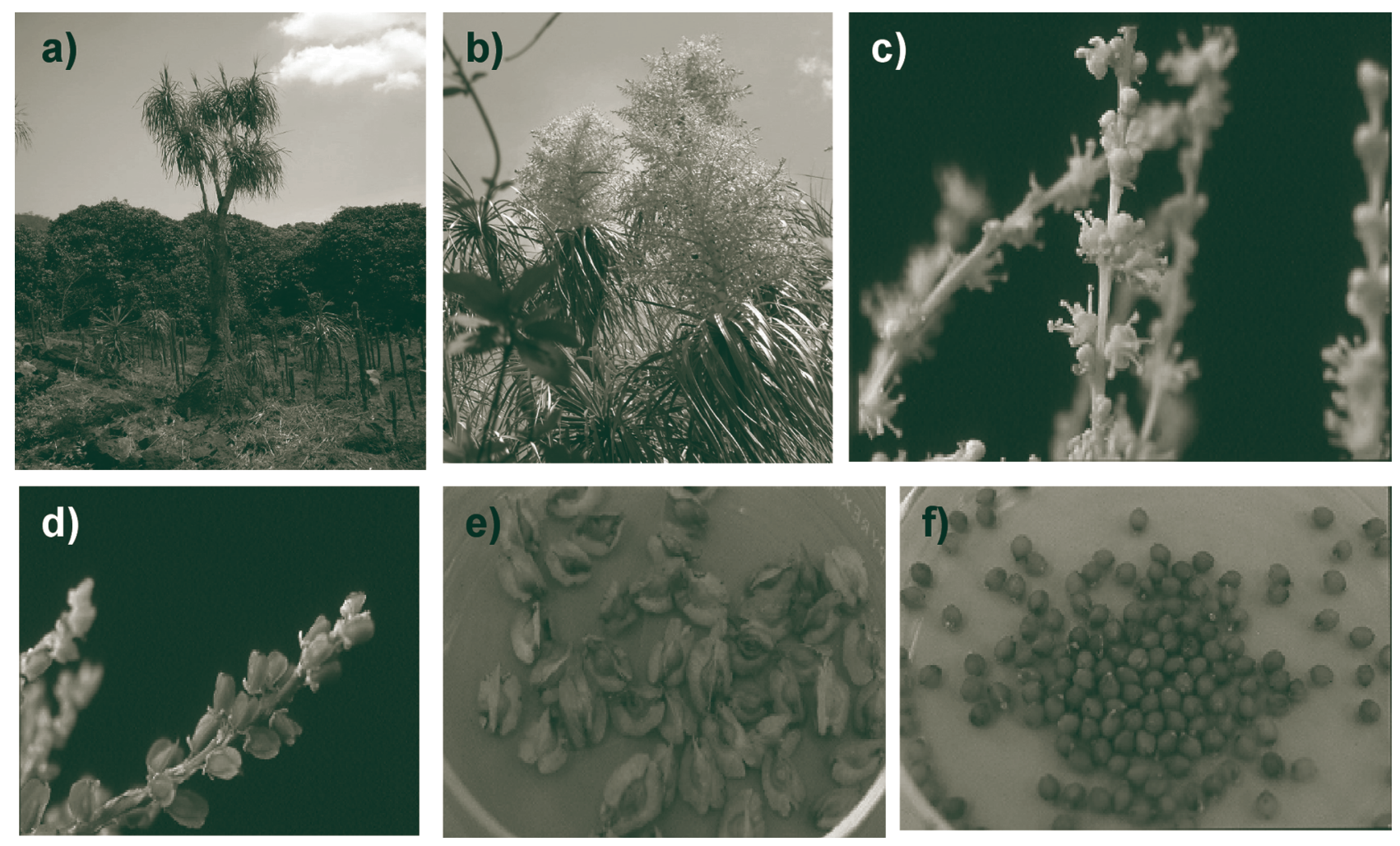

Figura 2. Esquema de a) individuo adulto, b) inflorescencia, c) flor masculina, d) formación del fruto, e) fruto maduro y f) semilla. 


\section{DESCRIPCIÓN DE Beaucarnea recurvata (Lemaire, 1861)}

Especie arbórea: monocotiledónea, dioica, de 4 a 15 m de alto, con ramificación abundante; base globosa, 2 - $3 \mathrm{~m}$ de diámetro, $2 \mathrm{~m}$ de altura, gruesa, lisa, gris oscuro a café oscuro; corteza dispuesta en patrones de cuadros cortos; ramas alargadas, gruesas y quebradizas; con hojas en forma de roseta (Fig. 2 a).

Hojas: recurvadas, lineales, 100 a $150 \mathrm{~cm}$ de largo, 10 a $20 \mathrm{~mm}$ de ancho, verde pálido; margen verde amarillo, denticulado; dentículas generalmente persistentes; base de la hoja triangular $(5$ a $7 \mathrm{~cm}$ largo, 4 a $5 \mathrm{~cm}$ de ancho).

Inflorescencia: ovoide de 0.7 a 1.0 m largo, rojo a amarillo paja; tallo de la inflorescencia de 20 a 30 $\mathrm{cm}$ de largo, 1.0 a $1.5 \mathrm{~cm}$ de diámetro; las ramas primarias ligeramente onduladas, pedúnculo de (15) 20 a $30 \mathrm{~cm}$ de largo, la parte superior de 10 a $15 \mathrm{~cm}$ de largo; brácteas del pedúnculo y de las ramas casi triangulares y largo acuminado; las ramas más altas de 5 a $8 \mathrm{~cm}$ de largo con 18 a 24 nodos florales (Fig. 2 b).

Flores masculinas: 2 a 3 por nodo; pedicelo 1.5 a $2.0 \mathrm{~mm}$ articulado cercano a la flor; segmento del perianto ovado, 2.0 a $2.5 \mathrm{~mm}$ de largo, inserción del filamento en la parte superior de la antera; anteras fuertemente sagitadas (Fig. 2 c).

Flores femeninas: de 1 a 2 ( 3 a 4) por nodo; pedicelo 2.5 a 4(-5) $\mathrm{mm}$ de largo articulado sobre la mitad; segmento del perianto elíptico a ovado, 1.5 a $2.0 \mathrm{~mm}$ largo; ovario escasamente auriculado, nectarios basales; lóbulo estigmático escasamente lanceolado.

Fruto: pedúnculo del fruto 3 a $5(-6) \mathrm{mm}$ de largo. Fruto elipsoide a ligeramente obovado, 12 a 14 $\mathrm{mm}$ de largo, 9 a $10 \mathrm{~mm}$ de ancho, amarillo pálido, la muesca apical $1 \mathrm{a} 2 \mathrm{~mm}$ de largo y ancho; estilo ensanchado hacia arriba de $2 \mathrm{~mm}$ de largo (Fig. $2 \mathrm{~d}$ y e).

Semilla: semilla elipsoide y en gran parte ovoide, 3.5 a $4.5 \mathrm{~mm}$ de largo, 3 a $4 \mathrm{~mm}$ de ancho, lóbulo no bien marcado; testa escabrosa a liso, rojo café brillante (Fig. $2 \mathrm{f}$ ).

Sinónimos: Nolina recurvata (Lem.) Hemsl. 1884, Dasylirion recurvatum (Lem.) J. F. MacBr. 1918, Beaucarnea tuberculata Roezl 1883, Beaucarnea inermis (S. Watson) Rose 1906, Dasylirion inerme S. Watson 1891. El nombre válido es Beaucarnea recurvata Lemaire (1861).

\section{DESCRIPCIÓN Y DINÁMICA DE LA ESPECIE}

El aprovechamiento que hacen los campesinos de los recursos silvestres generalmente se fundamenta en el conocimiento de su entorno natural. Sabemos que los nombres locales de las especies varían según la cultura. Al realizar recorridos de campo en la región centro de Veracruz se puede observar que la monja se encuentra en algunos pueblos, también en los potreros y solares de las casas campesinas. Es una especie llamativa que ha sido conservada y en ocasiones sembrada.

\section{DISTRIBUCIÓN Y HÁBITAT}

La familia Nolinaceae es endémica de Norteamérica y parte de Centroamérica. El género Beaucarnea se distribuye desde México hasta Centro América, actualmente se reconocen alrededor de once especies, de las cuales ocho son endémicas del país. Todas las especies de Beaucarnea en México se encuentran en un estrecho rango de distribución en regiones semiáridas y de selva baja caducifolia, en el Norte, Sur y Sureste de México (HERNÁNDEZ, 1992; 1993a; 1993b) crecen en suelos rocosos deficientes en nutrientes, en acantilados y montañas con fuerte pendiente (HERNÁNDEZ 1993b; CARDEL et al., 1997).

La mayoría de las poblaciones de Beaucarnea se encuentran en estado crítico por la continua fragmentación y destrucción de su hábitat, ocasionado por la expansión de la frontera agrícola y ganadera, extracción de leña, madera y crecimiento urbano. Por otro lado la extracción de semillas, plántulas e individuos juveniles y adultos, afectan no sólo el 
tamaño de la población sino también la proporción de sexos, reduciendo las posibilidades de fertilización y la producción de semillas. Este proceso de explotación expone a las especies a un estado de amenaza o posible extinción, a través de la reducción del tamaño mínimo viable de las poblaciones, así como al deterioro de la diversidad genética de las mismas (ELLSTRAND \& ELAM, 1993; NASON \& HAMRICK, 1997).

La reducción y fragmentación de las selvas es una de las mayores amenazas para las poblaciones naturales de árboles en las zonas tropicales. Afecta los patrones de apareamiento y de éxito reproductivo y flujo genético de especies de árboles tropicales al reducir la actividad de los polinizadores, la dispersión del polen y los niveles de entrecruzamiento (TREJO \& DIRZO, 2000).

B. recurvata es una especie endémica que sólo se distribuye en los estados de Oaxaca y Veracruz. Está considerada como amenazada en la Norma Oficial Mexicana (SEMARNAT, 2002b). Su hábitat es la selva baja caducifolia (MIRANDA \& HER-
NÁNDEZ-X., 1963) ó bosque tropical caducifolio (RZEDOWSKI, 1978).

La selva baja caducifolia (SBC) abarca 32.5 millones de hectáreas en 578 municipios y 21 estados de México. La distribución de esta zona cubre porciones importantes de la planicie costera del Pacífico, la Península de Yucatán, el centro de Veracruz, el sur de Tamaulipas y el occidente y sur de México (Fig. 3). Este hábitat ha sido muy transformado para uso agrícola (24\%), ganadero (20\%) y otros $(9 \%)$, de modo que a principios del decenio de 1980 sólo subsistía 45\% de la cubierta de este tipo vegetal (TOLEDO \& ORDÓÑEZ, 1998). En el estado de Veracruz, al igual que en el país, la destrucción de este hábitat ha sido ocasionada principalmente por la expansión agrícola. Desde el punto de vista biológico, esta zona tiene alto índice de endemismos, estimado en $40 \%$ y presenta una diversidad florística total calculada en 6000 especies (RZEDOWSKI, 1978).

Los fragmentos de SBC ubicados en la parte media de las cuencas del río Actopan y La Anti-

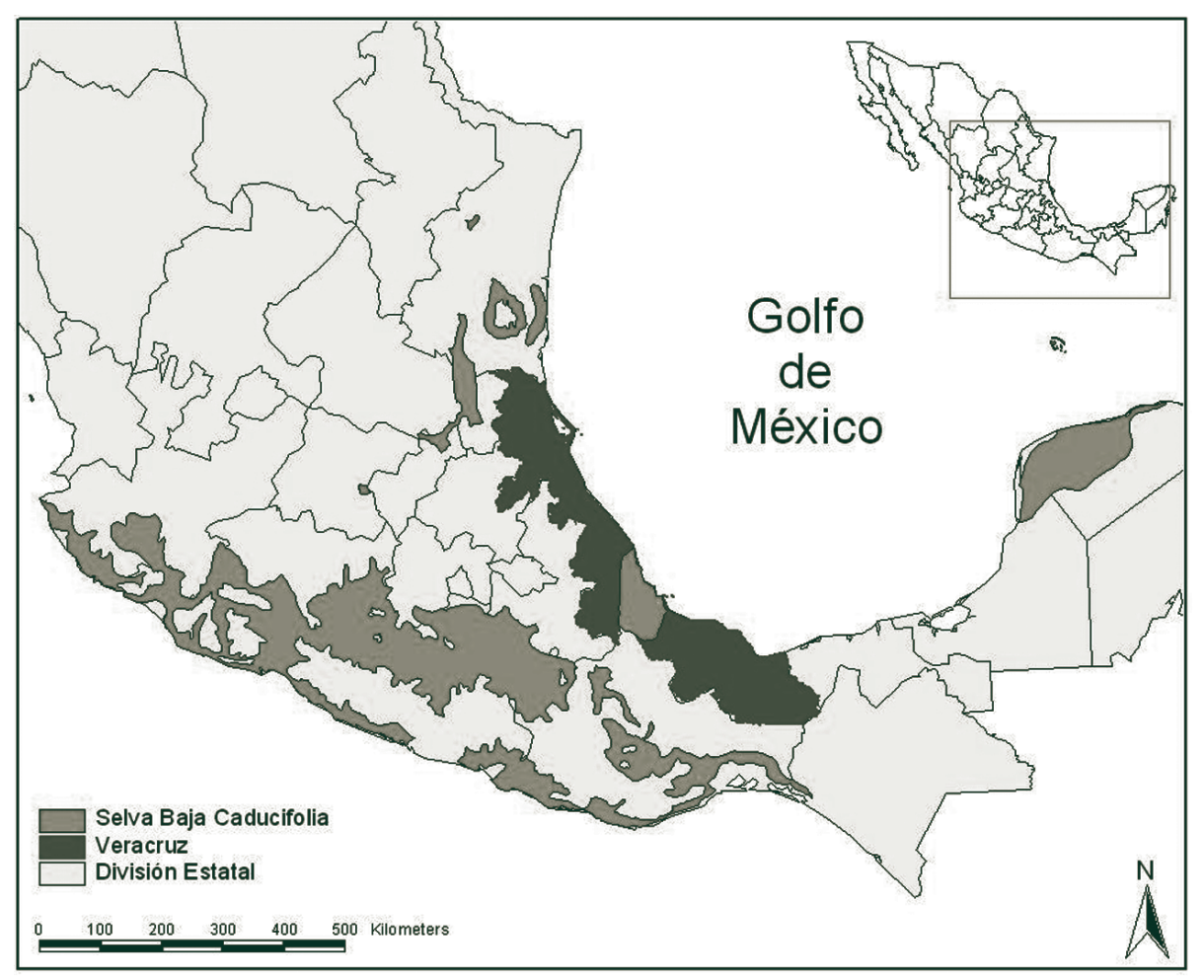

Figura 3. Distribución de la selva baja caducifolia en México. Rzedowski 1991. 

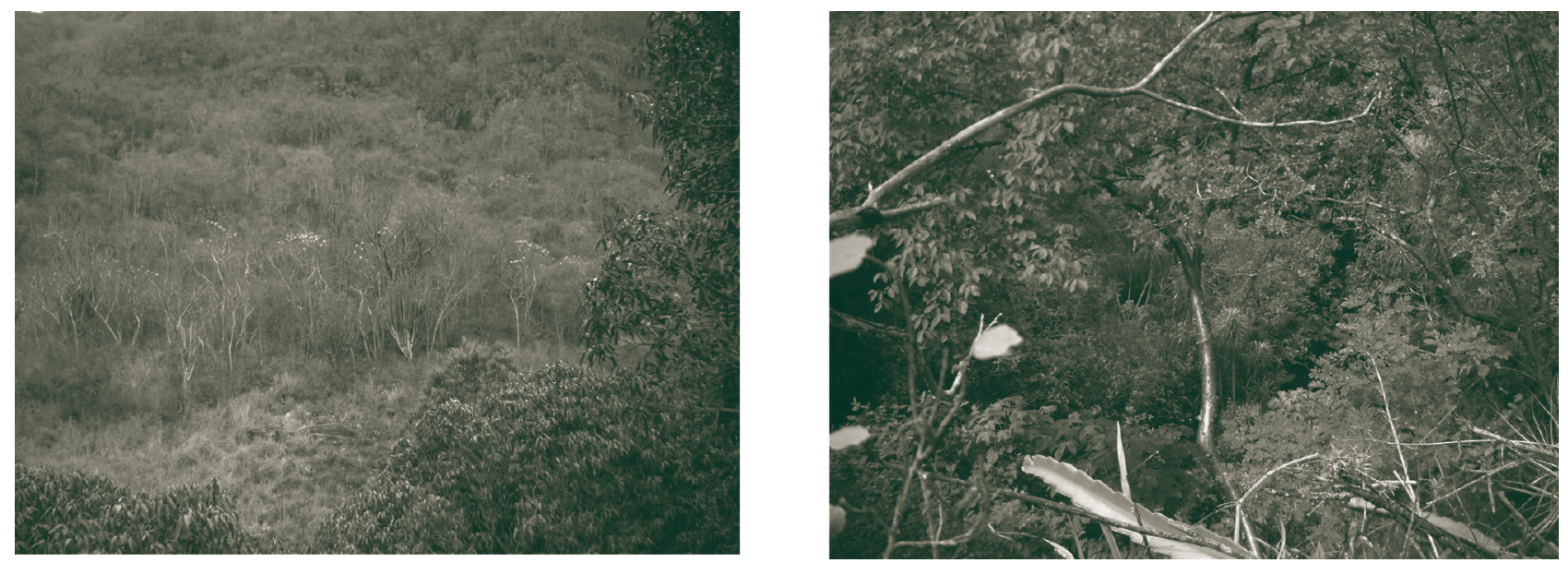

Figura 4. Aspecto de la sbc en diferente época, de secas (febrero) y lluvias (julio).

gua del centro de Veracruz, se consideran áreas de refugio para un conjunto importante de especies (ORTEGA, 1981; CASTILLO-CAMPOS, 1995); donde se reportan alrededor de 42 especies de plantas endémicas a la región o a México (CASTILLOCAMPOS, 2003).

La SBC constituye el límite térmico e hídrico de los tipos de vegetación de las zonas cálido-húmedas. Se presenta en zonas con promedios de temperaturas anuales superiores a $20^{\circ} \mathrm{C}$ y precipitación anual de $1200 \mathrm{~mm}$ como máximo, aunque lo común es que sean del orden de $800 \mathrm{~mm}$, con una temporada seca de 7 u 8 meses (noviembre a mayo). Estas selvas se presentan desde el nivel del mar hasta los $1700 \mathrm{~m}$.

La característica principal de esta selva es la escasa altura de sus componentes arbóreos (de 4 a $10 \mathrm{~m}$, eventualmente de $15 \mathrm{~m}$ ) y el hecho de que casi todas las especies pierden sus hojas durante un periodo de 5 a 7 meses, lo cual provoca un contraste enorme en la fisonomía de la vegetación entre la temporada seca y la lluviosa (Fig. 4).

Las formas de vida suculentas son frecuentes, especialmente en los géneros Agave, Opuntia, Selenicereus y Cephalocereus (CASTILLO-CAMPOS, 2003). Esta selva se desarrolla preferentemente en terrenos de ladera, pedregosos, con suelos bastante someros arenosos o arcillosos con drenaje superficial (Fig. 5).

La generación de conocimientos científicos sobre este tipo de selva, requiere un profundo conocimiento de las necesidades de las poblaciones humanas que ahí viven. Sólo así podrán desarrollarse estrategias para el manejo sustentable de la riqueza contenida en ellas (CONTRERAS \& BARRERA, 2007).
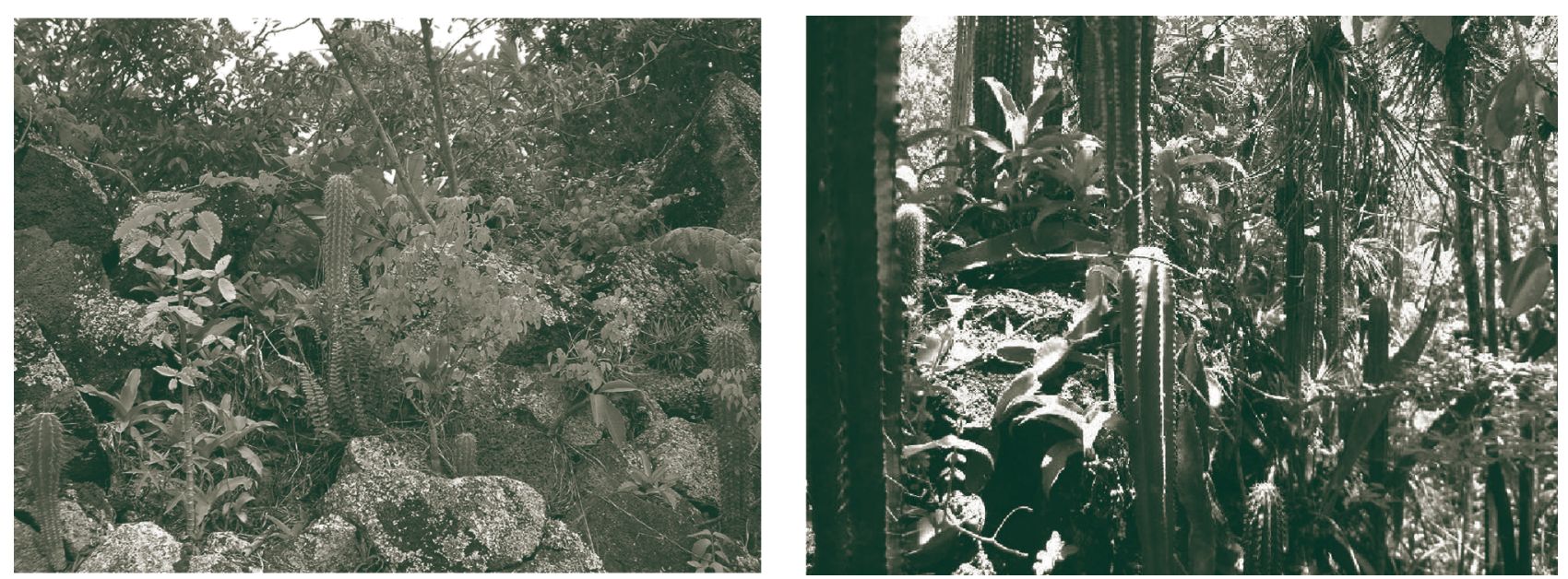

Figura 5. Detalle de las formas de vida y sustrato donde se desarrolla. 
La comercialización de la planta es ilegal en su mayoría, sólo existen en Veracruz, dos Unidades de Manejo y Aprovechamiento de B. recurvata registrados ante la SEMARNAT, La UMA “3 de Mayo" y el vivero "Mundo Verde", los ejemplares de esta especie se comercializan ilegalmente en viveros a nivel local y nacional, así como en el extranjero se ofertan semillas e individuos juveniles y adultos por Internet.

La fuerte demanda por esta especie en los últimos años, ha incrementado la venta ilegal, haciendo que este comercio salga del control de las instituciones encargadas de su regulación. No obstante, existe normativa que permite hacer el aprovechamiento legal de la especie. Esto requiere de la acción coordinada entre los productores, sociedad civil, instituciones de investigación y del gobierno.

\section{CONSIDERACIONES FINALES}

Los campesinos identifican y valoran sus recursos, sin embargo la mayoría carecen de los medios técnicos y económicos para aprovecharlos. Las especies de al to valor biológico y económico pueden incorporarse a los procesos productivos, facilitando la conservación de la biodiversidad. Al diversificar la producción se obtienen recursos económicos adicionales que pueden contribuir a mejorar el nivel de vida de las comunidades rurales. La Unidades de Manejo y Aprovechamiento de Vida Silvestre (UMAs), administradas por los propietarios del recurso, pueden ser una forma de conservar y aprovechar los recursos de la región, paulatinamente la palma monja, que contrarreste el comercio ilegal y la destrucción de su hábitat. La investigación participativa, junto con una mayor coordinación interinstitucional, son el modo idóneo para incidir en las acciones y políticas de conservación.

\section{BIBLIOGRAFÍA}

AGUIRRE, J. A. 1993. Producir conservando y conservar produciendo: Marco para la educación e investigación en ecología económica. Revista Forestal Centroamericana. 5: 10-14.

BOCCO, G. 1998. Naturaleza y Sociedad. Escalas de Espacio y Tiempo. Ciencias. 51: 54-59.
CARDEL, Y., RICO-GRAY, V. GARCÍA-FRANCO, J. \& THIEN, B. L. 1997. Ecological Status of Beaucarnea gracilis, an Endemic Species of the Semiarid Tehuacán Valley, México. Conserv. Biol. 11(2):367-374.

CASTILlO-CAMPOS, G. 1995. Ecología del paisaje del municipio de Jalcomulco, Veracruz. Tesis de Maestría. Facultad de Ciencias, UNAM. México, D. F. 190 pp.

CASTILLO-CAMPOS, G. 2003. Biodiversidad de la Selva Baja Caducifolia en un sustrato rocoso de origen volcánico en el Centro de Veracruz, México. Tesis Doctoral. UAM-Iztapalapa, México, D.F. 209 pp.

CONTRERAS, H. A. \& BARRERA, O. 2007. Caracterización de los sistemas agrarios asociados a los pedregales con alta biodiversidad en la cuenca del río Actopan, Veracruz. En: A. CONTRERAS \& S. CÓRDOVA (Coord.) Producción Agraria y recursos naturales. Asociación Mexicana de Estudios Rurales e Imprenta de Juan Pablos. Pp. 94-119.

ELLSTRAND, N. \& ELAM, R. 1993. "Population genetic consequences of small population size: Implicationes for Plant Conservation”. Annu. Rev. Ecol. Syst., 24: 217-242.

HERNÁNDEZ, L. 1992. Una especie nueva de Beaucarnea (Nolinaceae). Acta Bot. Méx. 18: 25-29.

HERNÁNDEZ, L. 1993a. Beaucarnea ¿Un género amenazado? Cact. Suc. Mex. 38:11-13.

HERNÁNDEZ, L. 1993b. Cladistic analysis of the American genera of Aspararagales and the systematic study of Beaucarnea (Nolinaceae) and Hemiphylacus (Hyacinthaceae). $\mathrm{PhD}$ thesis, Austin, USA: The University of Texas.

MIRANDA, F. \& HERNÁNDEZ-X. E. 1963. Los tipos de vegetación de México y su clasificación. Bol. Soc. Bot. Méx. 28:29-72.

NASON, J. \& HAMRICK, J. 1997. Reproductive and genetic consecuences of forest fragmentation: two case studies of Neotropical canopy trees. J. Hered. 88: 264-276.

ORTEGA, R. 1981. Vegetación y flora de una corriente de lava (mal país) al noreste del Cofre de Perote, Ver. Biótica Vol. 6 (1): 57-97. 
RZEDOWSKI, J. 1978. Vegetación de México. Limusa. México. 432 pp.

RZEDOWSKI, J. 1991. Diversidad y orígenes de la flora fanerogámica de México. Acta Bot. Mex. 14:3-21.

SEMARNAT 2002a. Programa Nacional del Medio Ambiente y Recursos Naturales. Programa estratégico para conservar los ecosistemas y su biodiversidad. México. $21 \mathrm{pp}$.

SEMARNAT, 2002b. Norma Oficial Mexicana. NOM-059-ECOL-2001, Protección ambientalEspecies nativas de México de flora y fauna silvestre-Categorías de riesgo y especificaciones para su inclusión, exclusión o cambio-Lista de especies en riesgo. Diario Oficial de la Federación (6 de marzo de 2002). Pp. 1-81.

TOLEDO, M. V. \& ORDÓŃEZ, M. J. 1998. El panorama de la biodiversidad de México: una revisión de los hábitats terrestres. En: T. P. Ramamoorthy, Bye, R., Lot, A. y Fa, J. (compiladores). $\mathrm{L} a$ diversidad biológica de México. Orígenes y distribución. Instituto de Biología. UNAM. México. Pp. 739-757.

TREJO, I. \& DIRZO, R. 2000. Deforestation of seasonally dry tropical forest: a national and local analysis in Mexico. Biological Conservation 94: 133-142. 